\title{
A POPULAR AND IMPORTANT TOOL FOR FORECAST USERS: JUDGMENTAL ADJUSTMENTS
}

\author{
M. Sinan GÖNÜL*
}

\begin{abstract}
'Judgmental adjustments' constitute one of the popular and important tools in the arsenal of the forecasting practitioners that facilitate the integration of their judgment into the forecasting process. In the current article, a literature review on this widely used method is provided. The motivation and reasons behind judgmental adjustments are examined followed by the recent concentrations of research on the subject. At the same time, primary research gaps are identified and an agenda for future research is provided.
\end{abstract}

Keywords: Judgmental adjustments, judgment, forecasting.

Öz

\section{Tahmin Kullanıcılarının Hizmetindeki Popüler ve Önemli Bir Araç: 'Yargisal Düzeltmeler'}

'Yargısal düzeltmeler', tahmin kullanıcılarının yargılarını tahminleme sürecine katmasına olanak veren popüler ve önemli araçlarıdır. Bu çalışmada, pratisyenler tarafindan oldukça yaygın olarak kullanılan bu metot hakkında bir literatür derlemesi yapılmıştır. Yargısal düzeltmelerin altında yatan sebep ve motivasyonlar anlatılmış ve ardından da son yıllarda bu konuyla ilgili yapılan bilimsel araştırmaların yoğunlaştığı alanlar incelenmiştir. Aynı zamanda, varolan araştımalardaki bazı önemli firsatlar gösterilmiş ve gelecekteki yeni araştırmalar için bir gündem oluşturulmuştur.

Anahtar Sözcükler: Yargısal düzeltmeler, yarg1, tahminler.

\footnotetext{
* Assoc.Prof.Dr., Department of Business Administration, Middle East Technical University, 06800 Ankara/TURKEY, msgonul@ metu.edu.tr
} 


\section{INTRODUCTION}

Forecasting is one the fundamental functions of organizations (Syntetos, Boylan, Disney, 2009: 149-160). It facilitates sharing of information in the form of systematic predictions with the purpose of managing uncertainty surrounding the future events. In undertaking this crucial function, there are generally two distinct roles among forecasting practitioners. The forecasters may either assume the role of 'forecast providers' or the role of 'forecast users' (Önkal, Gönül, 2005: 13). In the provider role, the main emphasis is on the generation and supply of forecasts. The gathering of data, selection and implementation of appropriate quantitative/qualitative methods and the subsequent generation of forecasts constitute the primary features. On the other hand, the second role, namely the 'forecast user' role, presumes the perspective of the managers or decision makers, who actually demand, acquire and use these predictions that are generated by the 'providers'. In this role, forecasts serve as important aids in the strategy formation and the decision making processes of the managers.

It can be argued that skill/competence set and the work-related responsibilities usually necessitate the managers to adopt the role of a 'forecast user'. In dealing with their various obligations, the managers usually do not have the chance to build up the necessary proficiency nor do they have the luxury of dedicating time and effort to the production of forecasts. It seems to be a better strategy to leave the job of forecast generation to more technical staff in the dedicated departments and/or choose to acquire them from specialized external sources. In this strategy, the decision makers do not allocate their resources to the generation of the forecasts, but simply delegate the job to some exterior providers.

However, by donning this 'user' role, the managers refrain themselves from contributing to the process of forecasting. They will no longer be involved with the generated numbers, and this situation will result in the acquired predictions to feel somewhat distant, cold and alien to the decision makers. Therefore the managers are in dire need of methods in order to earn back these numbers, in order to contribute to the process, or simply to attain a sense of familiarity with the predictions. On this matter, judgmental adjustments performed on these externally acquired forecasts seem to be the most 'natural' way (Önkal, Gönül, 2005: 13; Lawrence et al., 2006: 493-518).

There are two components in the judgmental adjustment process. The first component is the provided forecasts, which function as the 'baseline' for the adjustments. These forecasts are generally generated quantitatively, though qualitatively-generated forecasts are also frequently encountered (e.g., Lim, O'Connor, 1995: 149-168). The forecast providers usually produce these 
baseline forecasts and convey them to the forecast users. The second component is the judgment applied on these baseline forecasts by the users. Conducting judgmental adjustments allows the practitioners to integrate their intuition and knowledge into the already produced forecasts and hence they can put their "touch" into these predictions. By this way, they will regain a sense of ownership and a sense of intimacy with these externally generated predictions (Önkal, Gönül, 2005: 13). This feature, alone, strongly suggest that forecast adjustments are highly important and in fact 'inevitable' (Carbone et al., 1983: 559). Quite expectedly forecasting literature provides extensive evidence on the presence and popularity of judgmental adjustments in real business settings (Mathews, Diamantopoulos, 1986: 3-10, 1989: 129-140, 1990: 407-415; Diamantopoulos, Mathews, 1989: 51-59; Sanders, Manrodt, 1994: 92-100; 2003: 511-522, Klassen, Flores, 2001: 163-174; Önkal, Gönül, 2005: 13-17; Syntetos et al., 2009: 72-81; Fildes et al., 2009: 3-23).

Judgmental adjustments are also closely related with the level of acceptance of the provider forecasts. Upon receipt of an external forecast, the decision maker either accepts the forecast fully, or applies an adjustment on it based upon his judgment. This judgmental adjustment will be in direct proportion to the extent of his acceptance. If the forecasts are broadly acceptable, the adjustments tend to be smaller and less frequent (Gönül et al., 2006: 1481-1493, Önkal et al., 2008: 213-238); just enough to insert the 'touch' of the decision maker. However, if the forecast is largely unacceptable, the decision maker either applies excessive adjustments on it or completely discards it in the extreme case. In this sense, judgmental adjustments do not come in black \& white, but operates in tones of gray with the magnitude and frequency varying dependent on the degree of acceptance.

Resembling many organizational processes, the forecast acceptance and adjustment process is not perfect and has its shortcomings and caveats. There is evidence that adjustments that are conducted may not always produce beneficial results (e.g. Carbone et al., 1983: 559-566; Sanders, Ritzman, 2001: 405-416; Fildes, Goodwin, 2007: 570-576). On these occasions, the application of adjustments may actually lead to a worsening in the performance of the forecasts and therefore should be avoided or confined in their application. It then becomes of critical importance to identify these occasions, extend our knowledge and increase our understanding on this popular and 'inevitable' forecasting practice in the attempt for improvement.

Hence, in the current paper, the primary aim is to provide a brief review on the subject of "judgmental adjustments" in order to present its state-of-theart and report some of its recent findings. At the same time, the research gaps in the literature requiring more refined and more directed studies will be 
highlighted. In this respect, the ultimate motive is to make a strong call for academicians to conduct future research on this highly practitioner oriented and applied area that carries critical importance for the forecasting function within organizations. The plan of the paper is as follows: In the next section the motivation and reasons behind judgmental adjustments will be reviewed followed by the three primary research concentrations on the subject i) judgmental adjustments conducted in the absence of contextual information; ii) judgmental adjustments with contextual information; iii) judgmental adjustments conducted with the help of various decision aids. The paper will conclude with a 'discussion and directions for future research' part.

\section{THE REASONS AND MOTIVATIONS BEHIND JUDGMENTAL ADJUSTMENTS}

As portrayed in the introduction part, there appears to be multitude of reasons for judgmentally adjusting the baseline forecasts. To shed a light on these motivations of the forecasting practitioners, Önkal, Gönül (2005: 13-17) have conducted a series of interviews. Based on these interviews, the main reasons behind judgmental adjustments are i) to integrate the intuition and experience of the decision makers into the mechanical numbers; ii) to incorporate irregular events and rare occasions that may have not been caught by the forecast generation method; iii) incorporating privileged/insider information that cannot be known by the forecast providers; iv) to feel responsible and to feel in control of the forecasting process; v) to accommodate the expectations and perspective of the forecast users into the predictions and vi) to correct for biases that may been introduced during various stages of forecast generation. The researchers also stated that the forecast practitioners are extremely fond of judgmental adjustments and see them as a way of contributing to the forecasting process as well as a way of completing and owning the forecasts. Önkal, Gönül (2005: 13-17) also inquired some of the occasions where judgmental adjustments are not preferred or are somewhat refrained. These situations are i) when the technique with which the forecasts are produced is well-known and well-understood by the practitioner; ii) when the rationale or method underlying the forecast generation is well-justified through direct-communication or explanations; iii) when scenarios and/or alternative forecasts accompany the predictions; iv) when the source of the forecasts is perceived to be reliable and trustworthy and v) quite apparently when there exists a strict company policy that forbids judgmental adjustments. In these circumstances, the practitioners have reported that their acceptance of the provider forecasts is greater and hence their adjustments are smaller and less frequent. 
To refine and extend these findings, Gönül, Önkal and Goodwin (2009: 19-37) conducted a survey study with a larger number of forecasting practitioners. A total of 124 professionals attended the survey and the majority of the respondents were partners/owners of the company (approximately 47\%), $\mathrm{CEO} /$ members of executive board (approximately 17\%) and mid-level managers (approximately 28\%). The remaining $8 \%$ of the decision makers were among the members of staff. All of them were active forecast users. More than $40 \%$ of these decision makers had over four years of experience in using forecasts for their decisions. A further $30 \%$ had been users of forecasts for more than nine years. This portfolio of decision makers were requested to rate their reasons of conducting judgmental adjustments in terms of their importance and frequency. The results obtained were largely consistent with the findings from their previous study. The most prevalent motivation for adjusting was when the practitioners thought they could make a contribution to the forecasts i.e. to integrate their knowledge and intuition into the prediction; when there were special and rare events that should be taken into account (but supposedly had not been done by the providers) and interfering when there is an extreme and highly unexpected prediction. To be in control and shoulder the responsibility of the predictions was a quite frequent reason as well. The most important reason of not adjusting (i.e. accepting) a forecast was related with how persuasive that prediction or the accompanying material was. When the forecast is generated with a well-established method, reported with a persuasive language/style or accompanied by convincing explanations, the motivation to adjust is said to diminish.

On this subject, another related point is the nature of the underlying cognitive mechanisms behind judgmental adjustments (Goodwin, Wright, 1994: 553-568). This process may owe its existence to the well documented heuristic of 'anchoring and adjustment' (Tversky, Kahneman, 1974: 1124-1131). This heuristic briefly states that during the decision making process, we often start from a certain (may be relevant or irrelevant) initial point (i.e. an anchor) and arrive in our final judgments by making adjustments on it. If this heuristic is indeed under operation, the baseline forecasts may serve as the anchor point and then forecast users may be applying adjustments on this anchor as a result of using this mental mechanism. Another perspective on the process is that when forecasts users encounter an already-generated forecast, they compare this prediction with a prototype or a past 'analogous' event (Lee et al., 2007: 377390) in their minds and based upon the resemblance of the two, they may adjust the external forecast to make it similar to what they had in their minds. If this is the case, 'representativeness heuristic' (Tversky, Kahneman, 1974: 1124-1131) might be in command of the judgmental adjustment process. 
Eroğlu and Croxton (2010: 116-133) explored the impact of the personality characteristics and motivational orientation on the biases that may be introduced during judgmental adjustments. For these two factors they have found significant influence on the process. The last factor they have looked at 'locus of control' seems to have no impact on judgmental adjustments. In a concurrent study, Eroğlu and Knemeyer (2010: 179-195) also included the gender as a factor and found evidence on its impact on judgmental adjustments and the resulting performance. On a slightly different aspect, Gönül et al., (2012: 5-9) have suggested that feelings of 'trust' placed on the forecasts might also be influencing the process. Priming the mindset of decision makers for a corporate role (i.e., forecasting executive, marketing director or production director) through role-playing was also found to lead to differential judgmental adjustments (Önkal et al., 2011: 50-68).

Although all these studies attempted to define and clarify the underlying mechanisms and the subsequent biases of the adjustment process, many of the findings remain quite limited, and the cognitive nature of the process and its properties still remain largely unknown. Further research in this area is certainly required.

Having made these points, it's time to turn the attention to the conduct of judgmental adjustments. The literature on the subject can be broadly classified under three categories. These three categories will be reviewed next:

\section{JUDGMENTAL ADJUSTMENTS IN THE ABSENCE OF CONTEXTUAL INFORMATION}

Contextual information can be defined as any 'non-time series information' in the form of news, rumors or any additional piece of knowledge that are related with the forecasted event. This information can be something regarding the present or it can be something about the future. Whatever and however it is, contextual information provides a much richer context and understanding on the forecasted event. When no contextual information is available, forecast users have to content with whatever cues they can gather from the time-series data and the provided forecasts. Thus, on these occasions, the only sources of information they can use to form their adjustments are i) characteristics of the underlying time-series (Sanders, 1992: 353-364) and ii) the accuracy and reliability of the 'baseline' forecasts (Carbone et al., 1983: 559-566 ; Carbone, Gorr, 1985: 153-160; Willemain 1989: 179-185, 1991: 151154; Lim and O'Connor, 1995: 149-168; Goodwin et al., 2007: 391-404). 
The features of the time-series data (i.e. its structure, trend, variability etc.) constitute a major factor that affects the selection and implementation of the appropriate forecasting technique when generating the predictions. Similarly, it is quite natural to expect these characteristics to influence the judgmental adjustments as well. Sanders (1992: 353-364) investigated the effects of the time series features (trend, seasonality and noise) by using artificially constructed data to control for their levels. She discovered that judgmental adjustments of statistical forecasts generated on these series achieved higher accuracies when the series had low noise and when there was a discernible and identifiable pattern (like seasonality). Judgmental adjustment degraded in accuracy for high-noise series. Similarly, Lim and O'Connor (1995: 149-168) showed that the seasonality of the time-series data had an influence on the performance of judgmental adjustments.

One of the early studies that examined the accuracy and reliability of the baseline forecasts was conducted by Carbone et al. (1983: 559-566). In this study, the participants generated point forecasts with various methods and later on adjusted them. The authors have found that judgmental adjustments, overall, did not improve the accuracy of the initial forecasts; however the degradation in the performance was varying with respect to the generation technique. Even for one particular method, the accuracy level remained the same after adjustments. In this way, the researchers concluded that the nature of the baseline forecasts has an impact on the accuracy of the adjustments. Carbone and Gorr (1985: 153-160), extended this study by emphasizing the time-series characteristics through enhanced graphics. After this representation, the judgmental adjustments on the baseline forecasts were observed to have improved the accuracy.

Along similar lines, Willemain (1989: 179-185, 1991: 151-154) also utilized graphical presentations to exhibit the time-series data and the baseline forecasts. In 1989 study, the series were artificially constructed so that the accuracy levels of the baseline forecasts could be controlled. The researcher found that when the baseline forecasts had a substantial room for improvement the judgmental adjustments conducted on them could achieve increased accuracy. However, if the baseline forecasts are highly accurate, the judgmental adjustments had no effect on the performance, and may even lead to slight degradations in accuracy. The later study of Willemain (1991: 151-154) utilized a very similar setup, but used real time-series data instead of artificial ones. In this case, since there could be no strict control on the accuracy levels of the forecasts generated on these series, he could not achieve clear and distinct results. However, he reported that the results obtained, even though statistically insignificant, were in the same direction with the previous study. 
Lim and O'Connor (1995: 149-168) conducted a series of experiments to specifically manipulate the reliability of the baseline forecasts. The participants first generated initial forecasts judgmentally and then received statistical forecasts. Afterwards they were asked to adjust their initial predictions. For the statistical forecasts provided, there were two reliability levels: high and low. The findings from their research have designated that reliability of the baseline forecasts had a significant impact on the accuracy of judgmentally adjusted forecasts. The high-reliability group performed better than the low-reliability group. Moreover, in all reliability levels, the groups achieved some improvements in accuracy over their initial forecasts. Regardless, their final accuracies all remained lower than the accuracy of the statistical ones. Another observation was that the participants showed a tendency to place more weight on their initial forecasts, even when the provided statistical forecasts were highly reliable. This finding gives a hint that egocentric biases, or self-centered discounting effects may be in operation for judgmental adjustments, but this issue requires further elaboration through research.

A recent study on this subject explored the process of using a decision support system to facilitate the adjustment process (Goodwin et al., 2007: 391404). The proposed support system first presented the forecast practitioners with the time-series information. Based on the method selected by the practitioner, it also generated the baseline forecasts. Later on, the system allowed the practitioner to judgmentally adjust. The researchers have observed a different aspect of judgmental adjustment behavior with such a support system. If the practitioners failed to choose a method that fitted the times-series data well and hence failed to attain accurate and reliable baseline forecasts, they had a tendency to compensate this deficiency by making large judgmental adjustments on the predictions.

\section{JUDGMENTAL ADJUSTMENTS WITH CONTEXTUAL INFORMATION}

The research on judgmental adjustments under the influence of contextual information generally involves either laboratory studies that examine the effects of the contextual cues through experimentation (Lim, O'Connor, 1996: 139153; Goodwin, Fildes, 1999: 37-53; Goodwin, 2000: 85-99; Goodwin et al., 2011: 242-253) or studies conducted within real organizational settings, where the presence of contextual information is inevitable (Mathews, Diamantopoulos, 1986: 3-10, 1989: 129-140, 1990: 407-415; Diamantopoulos, Mathews, 1989: 51-59; McNees, 1990: 287-299; Sanders, Manrodt, 1994: 92-100, Klassen, Flores, 2001: 163-174; Deschamps, 2004: 647-657; Synthetos et al., 2009: 7281; Fildes et al., 2009: 3-23). 
To investigate the impact of contextual information on judgmental adjustments, Lim and O'Connor (1996: 139-153) used a similar task with their previous study (Lim, O'Connor, 1995: 149-168). The participants first judgmentally generated initial forecasts and then received statistical predictions. Afterwards they were asked to adjust their initial forecasts. The forecasted event was the sales of a soft drink on a hot summer day. The researchers artificially generated the data so that soft drink sales were highly correlated with the temperature. In this setting, the contextual information they had provided was the temperature on that day. The groups selectively received this information. One of the groups received no contextual information, the second group received somewhat-reliable information and the third group received highlyreliable contextual information. Their findings pointed out to the benefit of having contextual information. For groups receiving contextual information, there were improvements in the performance of judgmentally adjusted forecasts when compared against the initial forecasts and the forecasts judgmentally adjusted without contextual information. The high-reliability information group attained the highest accuracy level, even better than those of the provided statistical forecasts. The somewhat-reliable and no contextual-information groups did not achieve significant improvements over their initial forecasts.

Goodwin and Fildes (1999: 37-53) explored the effects of contextual information in interaction with the presence of irregular events (that affects the time series data) in an experimental setting. The sales data belonging to a product was used as the time-series and the contextual information was about the existence of sales-incentives. These sales-incentives (when present) served as the irregular events and led to additional amounts of sales for those periods. The participants were required to generate judgmental forecasts for both normal periods (where the incentives had no significant effects) and special periods (where the effects of incentives were significant). Some of the groups also received statistically generated baseline forecasts and were required to judgmentally adjust them. These statistical forecasts provided highly accurate predictions for normal periods, but they were not so accurate for the special periods since the statistical generation method could not foresee the presence of sales-incentives. Goodwin and Fildes (1999: 37-53) reported an interesting finding. The ability of the subjects to discriminate the occasions when they should accept the baseline forecasts versus when they should adjust them was flawed. It seems that forecasters could not make efficient use of the contextual information provided to them. In the ideal case, during normal periods forecasters should have accepted the statistical forecasts (since they were highly accurate), while during special periods they should have taken the (now lessaccurate) statistical forecasts as baseline and judgmentally adjust them in an attempt to improve their accuracy. Such a behavior was not observed. 
Extending from these findings, Goodwin (2000: 85-99) looked for novel ways that would discourage the forecasters from making large adjustments on reliable forecasts and directing them to employ appropriate adjustments to the less-reliable ones. He used a very similar setup with the previous study. In this case, he proposed three different elicitation methods. The first method was explicitly asking the participants whether or not they wanted to adjust after they were given the baseline forecasts. The second method was similar to the first one, but differed in the way that if the participants chose to adjust, they were required to convey only the amount of adjustment, not the final adjusted forecast. The third method built on the second method with the addition that if participants chose to adjust, then they were also asked to indicate their reasons for adjustment. There was one last group that received none of these elicitation methods and served as the control group. The findings were quite intriguing. During normal periods (when the statistical forecasts were highly reliable) the elicitation methods decreased the amount of adjustment conducted on the baseline forecasts, and ended up in improved accuracy when compared against the control group. There were no significant differences among the elicitation methods in terms of their effects on adjustment, but the third method seemed to be slightly more efficient than the others. During special periods, (when the statistical forecasts were less reliable) no significant differences were reported in terms of the adjustment size and the accuracy levels among the four groups. It seems that the elicitation methods discouraged the subjects from making excessive adjustments on accurate forecasts, but they had no effect when the statistical forecasts were less accurate and could benefit from judgmental adjustments.

A recent revival of interest on this topic involved the use of a forecasting support system (Goodwin et al., 2011: 242-253). The researchers utilized a similar setup with their previous studies, however for their current work; they utilized a support system to manage the process. The special feature of this system was that it either imposed restrictions on the judgmental adjustments (by prohibiting small adjustments) or it provided guidance (i.e. it advised the decision makers to adjust during special periods, but advised not to adjust during normal periods). There was one last group that did not receive any restriction or guidance and hence served as the control group. The results indicated that neither guidance nor restrictiveness of the decision support system was effective in improving the performance of the adjustments. Restrictiveness of the system not only reduced the unnecessary adjustments but also reduced the necessary and useful ones. At the same time, it led to extremely sized adjustments. Therefore the accuracy did not improve in this mode. On the other hand, the guidance given by the system was mostly ignored, so this mode was not useful either. It seems trying to mechanically restrict the judgmental adjustments or trying to crudely guide the decision makers without provoking 
meticulous thought processes are not the right way to improve the adjustment and acceptance process.

In another study, Önkal, Goodwin, Thomson, Gönül and Pollock (2009: 390-409) have presented the source of the baseline forecasts as the contextual information. They tried to investigate whether the same forecasts would be adjusted differently if their sources were thought to be different. Their results revealed supportive evidence. When exactly the same prediction was believed to originate from a statistical method, it was adjusted more extremely than the case when it was believed to originate from a human expert. Predictions generated by a human expert were accepted more. In a second study, they have provided two different baseline forecasts to the participants. There were three groups. The first group believed that both forecasts were generated by statistical methods, the second group was told that the forecasts were both generated by human experts and the third group was told that one of the forecasts was generated by a human expert, while the other one via statistical method. In this task, when the sources of the baseline forecasts were similar (either both are human experts or both are statistical) the adjustment patterns were quite similar to one another. However, when one forecast was believed to be from a human expert and the other one from a statistical method, the adjustments were in favor of the human expert. The predictions, supposedly, coming from a human expert received greater acceptance. Moreover, the researcher reported that overall, for every group, the judgmental adjustments improved the accuracy of the baseline forecasts.

Aside from these laboratory based research, there are also studies that explored the judgmental adjustments in their natural environment as being conducted in real life organizational settings (Mathews, Diamantopoulos, 1986: 3-10, 1989: 129-140, 1990: 407-415; Diamantopoulos, Mathews, 1989: 51-59; Sanders, Manrodt, 1994: 92-100, Klassen, Flores, 2001: 163-174; Synthetos et al., 2009: 72-81; Fildes et al., 2009: 3-23). It seems suitable to review these studies in this category, since in real organizational settings; the contextual information is an unavoidable part of the forecasting process and exerts a strong influence on the predictions.

Mathews and Diamantopoulos(1986: 3-10, 1989: 129-140, 1990: 407415; Diamantopoulos, Mathews, 1989: 51-59) conducted a series of studies over a couple of years by collecting and analyzing sales-forecast data from large manufacturing companies operating in UK. Their primary finding was that judgmental adjustments on quantitatively generated sales forecasts resulted in improved accuracy overall, and thus managers were encouraged to adjust judgmentally. In these studies, they have also investigated whether managers can effectively distinguish forecasts in need of adjustments from forecasts that 
are better left unadjusted. On this question, contrary to the laboratory based findings of Goodwin and Fildes (1999: 37-53), they have deduced that real life managers were efficient discriminators of forecasts which needed judgmental adjustments. In order to adjust, overall, the managers were selecting forecasts that would benefit more from the revision process (i.e., less-reliable forecasts with high error levels). However, one major limitation of these studies was the limited variety (in terms of the industry) of the manufacturing firms included. Most of these companies were operating in the health-care industry, and thus the generalizability of the results to other industries should be scrutinized.

The survey based research of Sanders and Manrodt (1994: 92-100) on US firms and Klassen and Flores (2001: 163-174) on Canadian firms provided further evidence that judgmental adjustments were quite widespread in practice. Sanders, Manrodt (1994: 92-100) reported that 45\% of the forecasting practitioners 'always' used judgmental adjustments on statistical forecasts, while the percentage of the remaining practitioners who told to have "sometimes" done so was 37\%. Klassen and Flores (2001: 163-174) stated that the $80 \%$ of the forecasting practitioners who have participated in their survey reported that they were judgmentally adjusting the quantitative forecasts they received.

The popularity of the judgmental adjustment process was once more shown through recent studies. Synthetos et al. (2009: 72-81) investigated the sales/demand forecasts of a major international pharmaceutical company and concluded that judgmental adjustments were quite common and resulted in improved accuracy for the demand forecasts. In a larger scale study, Fildes et al. (2009: 2-23) gathered more than 60,000 demand forecasts from four large supply chain companies in UK and investigated the conduct of judgmental adjustments. In all of these companies, the percentage of judgmentally adjusted forecasts over all forecasts was quite high, even rising up to $91 \%$ in one of those companies. The analysis of this large scale data revealed interesting findings. First, larger adjustments were resulting in higher accuracy than smaller adjustments. The authors have argued when there was a large adjustment; it was a portent that there was a need for intervention on these forecasts. This might be due to a special occasion or confidential information which would make a huge impact, but could not be captured or taken into account by the forecast generation method, so the managers had all the reasons to interfere. However, when there was a small adjustment, it signaled meddling with the forecasts to add the 'touch' of the decision maker. For those cases, the final accuracy was degrading. Second, negative adjustments (i.e. adjusting the baseline forecasts in the downward direction) were leading to higher accuracy than positive adjustments (i.e. adjusting the baseline forecasts in the upward direction). The researchers argued that this might be caused by the fact that a negative 
adjustment would only be applied if there is ample evidence that something would cause a downturn on the forecasted event. On the other hand, many of the upward adjustments are just done because of optimism and wishful thinking and hence were not based on realistic facts.

The studies conducted by McNees (1990: 287-299) and Deschamps (2004: 647-657) explored judgmental adjustments in a slightly different area. The researchers have chosen macroeconomic forecasting as their setting. Since macroeconomic forecasts utilize various pieces of information (like GNP, real GNP, treasury-bill rate, unemployment rate, etc.) in addition to time-series data, the presence of contextual (i.e. non-time series) information is unavoidable. Previous research on macroeconomic forecasting also hinted that judgment has a strong influence on the generation of macroeconomic predictions and adjustments based on judgment are quite common (Young, 1982: 189-204; Turner, 1990: 315-345; Donihue, 1993: 81-92; Clements, 1995: 410-420).

In his study, McNees (1990: 287-299) worked with some expert macroeconomic forecasters who were well-known at the time of the study. First, he asked these forecasters to generate macroeconomic point predictions quantitatively. Later on he asked these experts to judgmentally adjust their forecasts. The researcher had access to both the initial and the adjusted forecasts so he could make accuracy comparisons. These comparisons designated, overall, the accuracy of initial quantitative forecasts has improved through judgmental adjustments. However, the improvement was dependent on the macroeconomic forecast type and the forecast horizon. The accuracy of the forecasts decreased over longer horizons. Similar to the results of Lim and O'Connor (1995: 149-168), he also found a tendency of the experts to overweigh their own judgment. Deschamps (2004: 647-657) investigated the budget forecasting process in Washington State and observed that frequently applied judgmental adjustments has led to significant improvements in the forecasting accuracy.

\section{JUDGMENTAL ADJUSTMENTS CONDUCTED WITH THE HELP OF DECISION AIDS}

The research on judgmental adjustments with the presence of contextual information, overall, pointed out to the benefits of having additional material that will help decision makers in engaging the adjustment task. Starting from this point, many researchers looked for additional decision supplement materials as well as more innovative ways to manage and support the judgmental adjustment process. 
One stream of research explored the application of judgmental adjustments through systematic procedures. Some researchers have criticized judgmental revisions in the sense that they are applied on baseline forecasts in an informal and ad hoc fashion by forecast users (Bunn, Wright, 1991: 501-518; Bunn, 1996: 528-536). As a remedy against this mode of conduct, the application of judgment in a structured, methodological or rule-based manner was proposed. Some of the research done along these lines, tried to integrate well-established decision analysis techniques, e.g. analytic hierarchy processAHP (Wolfe, Flores, 1990: 389-405; Flores, Olson, Wolfe, 1992: 421-433; Yüksel, 2007: 1063-1070) to provide structure to forecast adjustment and acceptance process. Others have examined utilizing other quantitative tools/methods such as neural networks (Lee, Yum, 1998: 135-154), IF-THEN rules accompanied by fuzzy logic (Ghalia, Wang, 2000: 380- 397), computerized systems for the automated adjustments of baseline predictions (Lee, Oh, Shin, 1990: 39-49) and state-dependent parameter (SDP) estimation to correct the biases of the adjustments (Trapero et al., 2011: 490-508). Overall, all these studies reported to have achieved some improvements in the process. However, they carry problems of implementation. None of these studies documents the realization of these techniques in real-life organizational settings. They remain highly hypothetical and case-based. The forecast users require specialized training and have to allocate a lot of time and effort on the forecasting task if they want to use these systematic adjustment methods. Owing to these factors and given the fact there are various reasons and motivations behind adjustments, it seems quite difficult for these systems to find widespread implementation and utilization in organizations.

Gönül et al., (2006: 1481-1493) suggested the use of 'explanations'. They have argued that explanations serve as important vessels of communication and may constitute effective aids to create a bridge between forecast providers and forecast users. In this sense, if accompanied by explanations, the forecast acceptance and adjustment process might have been taken under control. In their study, with the baseline forecasts they have also attached explanations that give rationale/justification about the predictions. Within the experimental setup, they have manipulated the structural characteristics of the explanations, namely, the length and the style of language. The same contextual information (that justifies the forecasts) could be given in a precise and short explanation or it could be conveyed in a long and detailed manner. The style of the language can be either strong (heavy use of words such as "must", "should have", "certainly" etc.) or vague (heavy use of words such as "may be", "could be", "probably" etc.). Their results indicated that when the explanations were perceived to be valuable, they had a positive impact on the acceptance of baseline forecasts; the frequency and size of adjustments were smaller. A long and strongly worded 
explanation was more powerful in this effect. However, if a short explanation was required it was better to communicate it with a vague language.

In a later study, Önkal et al., (2008: 213-238), extended their research on explanations to investigate their influence in multi-tier adjustments. These are adjustments conducted on already adjusted forecasts. The authors argued that in organizations, the judgmental adjustment process is not confined with a onetime revision, but as predictions are processed and used in various departments and stages, multiple adjustments are observed unavoidably. Their findings indicated that the tendency to adjust was smaller if the decision makers thought that the forecasts they are presented with are already adjusted. The acceptance was even higher when an explanation was given on the reasons why the forecast was adjusted previously before it is received by the current decision maker. This effect persisted even though the same forecast was framed as a baseline forecast versus it is framed as an already adjusted forecast (in real it was not and the numbers were exactly the same). Both these studies have designated that if the forecast users can be persuaded there is a justifiable and well-thought process behind a provided baseline prediction (either through explanations or other ways), the decision makers were more prone to accept it without making any change. Otherwise, they had a greater tendency to apply their adjustments.

\section{DISCUSSION AND DIRECTIONS FOR FUTURE RESEARCH}

In this article, a literature review on "judgmental adjustments", a popular technique among forecasting practitioners is attempted with the purpose of presenting its state-of-the-art and informing about its recent concentrations of research as well as some of its recent findings.

Evidence from real organizations and real practitioners clearly indicate that judgmental adjustments are inexorable for the integration of judgment into the forecasting process. Despite this fact, we can still be considered to be infants in terms of the current stage of research on this technique. We have only touched the tip of the iceberg, and there is still a plethora of issues to investigate and discover.

Foremost, the cognitive mechanisms that command and affect the judgmental adjustment process are largely unknown. This area needs immediate attention in order to begin to properly understand the process. We need meticulously planned studies and cleverly designed experiments to pinpoint and isolate various mechanisms that may likely be under operation. Related with this issue, we also need research to enhance our knowledge on the discrimination ability of the forecast users. How do practitioners distinguish a 
forecast that needs adjustments from one that is better left unadjusted? What are the underlying mechanisms that influence the discrimination? And what is required to be a 'good' discriminator? Given the contradictory findings in literature, some directed research on this subject can shed some light.

This side of the story is about knowing 'when' to apply the judgmental adjustments. The other important side is about 'how' and 'how much' to adjust? And this part is directly related with the performance of the adjustments. On this venue, research so far offered mixed results. In terms of the performance, many studies provided evidence that judgmental adjustments achieved improvements in accuracy over the baseline forecasts. However, on many occasions, the adjustments were found to result in degraded accuracy. It is evident that judgmental adjustment process is not always beneficial and does not automatically end up in improved accuracy. It is highly dependent upon a multitude of factors.

The reliability of the baseline forecasts and the characteristics of the underlying time-series seem to be two of these factors. If the baseline forecasts are highly accurate, then the chances of improvement through judgmental adjustments are found to be quite slim. Hence, the conduct of adjustment is most beneficial where quantitative methods fail to provide accurate predictions. In this aspect, Sanders and Ritzman (2001: 405-416) asserted that when the forecasting environment is highly uncertain but is subject to predictable changes, that constitutes an excellent situation for the judgmental adjustments to rise and shine. The second factor is the presence of contextual information. If decision makers can access to relevant, reliable and true non-time series information, then their adjustments is likely to end up in an increased performance. Sanders and Ritzman (2001: 405-416) argued that when forecast users possess a good level of domain knowledge (i.e. when users are experienced in selecting, properly processing and integrating contextual information into their forecasts) and when contextual information exists, the judgmental adjustments become highly efficient.

The third factor is the presence of decision aids to help the forecast users in their adjustment process. On this factor, some researchers proposed systematic adjustment procedures and techniques. Even though, the underlying assumptions and purposes were in the right place, this stream remained quite secluded from practice and applied arena. Some further research on these techniques, with the forecast practitioners and real organizational implementation in focus can achieve success and help to close this gap. Other researchers have proposed the use of explanations to transmit the rationale and perspective of the providers to the users of forecasts. In fact, using explanations is just one of the many ways to improve the communication between the two 
sides of the coin, namely the ones who 'produce' the forecasts and the ones who 'use' them. The 'key' in attaining accurate judgmental adjustments also depends on the connection, mutual understanding and collaboration between these two actors that construct the forecasting function and future research in this direction that search for new aids and new methods is highly critical.

\section{REFERENCES}

Bunn, D.W. (1996) "Non-Traditional Methods of Forecasting”, European Journal of Operational Research, 92(3), 528-536.

Bunn, D.W., G. Wright (1991) "Interaction of Judgmental and Statistical Forecasting Methods: Issues and Analysis”, Management Science, 37, 501-518.

Carbone, R., A. Anderson, Y. Corriveau, P.P. Corson (1983) "Comparing the Different Time Series Methods: The Value of Technical Expertise, Individualized Analysis and Judgmental Adjustment”, Management Science, 29(5), 559-566.

Carbone, R., W. Gorr (1985) “Accuracy of Judgmental Forecasting of Time Series”, Decision Sciences, 16, 153-160.

Clements, M.P. (1995) "Rationality and the Role of Judgement in Macroeconomic Forecasting”, The Economic Journal, 105, 410-420.

Deschamps, E. (2004) "The Impact of Institutional Change on Fforecast Accuracy: A Case Study of Budget Forecasting in Washington State", International Journal of Forecasting, 20(4), 647-657.

Diamantopoulos, A., B. Mathews (1989) "Factors Affecting the Nature and Effectiveness of Ssubjective Revision in Sales Forecasting: An Empirical Study," Managerial and Decision Economics, 10, 51-59.

Donihue, M.R. (1993) "Evaluating the Role Judgment Plays in Forecast Accuracy", Journal of Forecasting, 12, 81-92.

Eroğlu, C., K.L. Croxton (2010) "Biases in Judgmental Adjustments of Statistical Forecasts: The Role of Individual Differences", International Journal of Forecasting, 26(1), 116-133.

Eroğlu, C., A.M. Knemeyer (2010) "Exploring the Potential Effects of Forecaster Motivational Orientation and Gender on Judgmental Adjustments of Statistical Forecasts", Journal of Business Logistics, 31(1), 179-195. 
Fildes, R., P. Goodwin (2007) “Against your better Judgment? How Organizations can Improve their use of Management Judgment in Forecasting”, Interfaces, 37(6), 570-576.

Fildes, R., P. Goodwin, M. Lawrence, K. Nikolopoulos (2009) "Effective Forecasting and Judgmental Adjustments: An Empirical Evaluation and Strategies for Improvement in Supply-Chain Planning", International Journal of Forecasting, 25, 3-23.

Flores, B.E., D.L. Olson, C. Wolfe (1992) "Judgmental Adjustment of Forecasts: A Comparison of Methods", International Journal of Forecasting, 7(4), 421433.

Ghalia, M.B., P.P. Wang (2000) "Intelligent System to Support Judgmental Business Forecasting: The Case of Estimating Hotel Room Demand", IEEE Transactions on Fuzzy Systems, 8(4), 380- 397.

Goodwin, P. (2000) "Improving the Voluntary Integration of Sstatistical Forecasts and Judgment", International Journal of Forecasting, 16, 85-99.

Goodwin, P., R. Fildes (1999) "Judgmental Forecasts of Time Sseries Affected by Special Events: Does Providing a Statistical Forecast Improve Accuracy?", Journal of Behavioral Decision Making, 12(1), 37- 53.

Goodwin P., R. Fildes, M. Lawrence, K. Nikolopoulos (2007) "The Rocess of using a Forecasting Support System”, International Journal of Forecasting, 23(3), 391-404.

Goodwin P., R. Fildes, M. Lawrence, G. Stephens (2011) "Restrictiveness and Guidance in Support Systems", Omega: The International Journal of Management Science, 39(3), 242-253.

Goodwin, P., G. Wright (1994) "Heuristics, Biases and Improvement Strategies in Judgmental Time Series Forecasting”, Omega: The International Journal of Management Science, 22(6), 553- 568.

Gönül, M.S., D. Önkal, M. Lawrence (2006) “The Effects of Structural Characteristics of Explanations on use of a DSS", Decision Support Systems, 42(3), 14811493.

Gönül, M.S., D. Önkal, P. Goodwin (2009) "Expectations, use and Judgmental Adjustment of External Financial and Economic Forecasts: An Empirical Investigation", Journal of Forecasting, 28, 19-37.

Gönül, M.S., D. Önkal, P. Goodwin (2012) "Why Should I Trust your Forecasts?", Foresight: The International Journal of Applied Forecasting, 27, 5-9. 
Önkal, D., M.S. Gönül (2005) "Judgmental Adjustment: A Challenge for Providers and users of Forecasts", Foresight: The International Journal of Applied Forecasting, 1(1), 13-17.

Klassen, R.D., B.E. Flores (2001) "Forecasting Practices of Canadian firms: Survey Results and Comparison", International Journal of Production Economics, 70(2), 163-174.

Lawrence, M., P. Goodwin, M. O'Connor, D. Önkal (2006) “Judgmental Forecasting: A Review of Progress over the Last 25 Years", International Journal of Forecasting, 22(3), 493-518.

Lee W.Y., P. Goodwin, R. Fildes, K. Nikolopoulos, M. Lawrence (2007). "Providing Support for the use of Analogies in Demand Forecasting tasks", International Journal of Forecasting, 23(3), 377-390.

Lee, J.K., S.B. Oh, J.C. Shin (1990) "UNIK-FCST: Knowledge-Assisted Adjustment of Statistical Forecasts”, Expert Systems with Applications, 1(1), 39-49.

Lee, J.K., C.S. Yum (1998) "Judgmental Adjustment in time Series Forecasting Using Neural Networks”, Decision Support Systems, 22, 135-154.

Lim, J.S., M. O'Connor (1995) "Judgmental Adjustment of Initial Forecasts - Its Effectiveness and Biases”, Journal of Behavioral Decision Making, 8(3), 149-168.

Lim, J. S., M. O'Connor (1996) "Judgmental Forecasting with Time Series and Causal Information", International Journal of Forecasting, 12(1), 139-153.

Mathews, B.P., A. Diamantopoulos (1986) "Managerial Intervention in Forecasting: An Empirical Investigation of Forecast Manipulation", International Journal of Research in Marketing, 3, 3-10.

Mathews, B.P., A. Diamantopoulos (1989) “Judgemental Revision of Sales Forecasts: A longitudinal Extension”, Journal of Forecasting, 8, 129-140.

Mathews, B.P., A. Diamantopoulos (1990) "Judgemental Revision of Sales Forecasts: Effectiveness of Forecast Selection”, Journal of Forecasting, 9, 407-415.

McNees, S.K.. (1990) "The Role of Judgment in Macroeconomic Forecasting Accuracy”, International Journal of Forecasting, 6(3), 287-299.

Önkal, D., M.S. Gönül, M. Lawrence (2008) “Judgmental Adjustments of PreviouslyAdjusted Forecasts”, Decision Sciences, 39(2), 213-238. 
Önkal, D., P. Goodwin, M. Thomson, M.S. Gönül, A. Pollock (2009) “The Relative Influence of Advice from Human Experts and Statistical Methods on Forecast Adjustments", Journal of Behavioral Decision Making, 22, 390-409.

Önkal, D., M. Lawrence, K.Z. Sayım (2011) "Influence of Differentiated Roles on Ggroup Forecasting Accuracy”, International Journal of Forecasting, 27(1), 50-68.

Sanders, N.R. (1992) “Accuracy of Judgmental Forecasts: A comparison”, Omega: The International Journal of Management, 20, 353-364.

Sanders, N.R., K.B. Manrodt (1994) "Forecasting Practices in U.S. Corporations: Survey Results", Interfaces, 24, 92-100.

Sanders, N.R., K.B. Manrodt (2003) "The Efficacy of Using Judgmental Versus Quantitative Forecasting Methods in Practice", Omega: The International Journal of Management Science, 31, 511- 522.

Sanders, N.R., L.P. Ritzman (2001) "Judgmental Adjustment of Statistical Forecasts" in J. S. Armstrong (ed.), Principles of Forecasting: A Handbook for Researchers and Practitoners, Mass:Kluwer Academic Publishers, 405-416.

Syntetos, A.A., J.E. Boylan, S.M. Disney (2009) "Forecasting for Inventory Planning: A 50-year Review", Journal of the Operational Research Society, 60, 149160.

Syntetos, A.A., K. Nikolopoulos, J.E. Boylan, R. Fildes, P. Goodwin (2009) "The Effects of Integrating Management Judgement into Intermittent Demand Forecasts”, International Journal of Production Economics, 118, 72-81.

Trapero J.R., R. Fildes, A. Davydenko (2011) "Nonlinear Identification of Judgmental Forecasts Effects at SKU Level", International Journal of Forecasting, 30(5), 490-508.

Turner, D.S. (1990) “The role of Judgement in Macroeconomic Forecastin”, Journal of Forecasting, 9, 315-345.

Tversky, A., D. Kahneman (1974) "Judgment under Uncertainty: Heuristics and Biases", Science, 185(4157), 1124-1131.

Willemain, T.R. (1989) "Graphical Adjustment of Statistical Forecasts", International Journal of Forecasting, 5, 179-185.

Willemain, T.R. (1991) “The Effect of Graphical Adjustment on Forecast Accuracy”, International Journal of Forecasting, 7(2), 151-154. 
Wolfe, C., B. Flores (1990) “Judgmental Adjustment of Earnings Forecasts”, Journal of Forecasting, 9, 389-405.

Young, R.M. (1982) "Forecasting with an Econometric Model: The Issue of Judgemental Adjustment", Journal of Forecasting, 1, 189-204.

Yüksel, S. (2007) "An Integrated Forecasting Approach to Hotel Demand", Mathematical and Computer Modelling, 46(7-8), 1063-1070. 